\title{
Características morfogênicas e estruturais de duas espécies de braquiária adubadas com diferentes doses de nitrogênio ${ }^{1}$
}

\author{
Cristina Cavalcante Félix da Silva ${ }^{2}$, Paulo Bonomo ${ }^{3}$, Aureliano José Vieira Pires ${ }^{3}$, Camila \\ Maida de Albuquerque Maranhão², Neusete Maria da Silva Patês ${ }^{2}$, Luciana Carvalho Santos ${ }^{2}$ \\ 1 Projeto financiado pela UESB. \\ 2 Pós-graduação em Zootecnia- UESB, Campus Juvino Oliveira, CEP: 75.7000-000, Itapetinga, BA. \\ ${ }^{3}$ DTRA - UESB, Campus Juvino Oliveira, Itapetinga, BA.
}

RESUMO - Objetivou-se com este estudo avaliar as características morfogênicas e estruturais de Brachiaria brizantha e $B$. decumbens adubados com diferentes doses de nitrogênio $(\mathrm{N})$. O experimento foi realizado em casa de vegetação, com quatro doses de nitrogênio (0,75, 150 ou $225 \mathrm{mg} / \mathrm{dm}^{3}$ ) e duas gramíneas (B. brizantha e decumbens), em um delineamento de blocos casualizados com cinco repetições. A adubação nitrogenada foi parcelada em três aplicações. A taxa de aparecimento foliar, o número total de folhas e o número de perfilhos por planta na B. decumbens foram maiores que na $B$. brizantha. No entanto, o filocrono, a taxa de alongamento foliar e a duração de vida da folha foram maiores na B. brizantha. A B. decumbens e a brizantha responderam de forma crescente até a dose de $190 \mathrm{mg} / \mathrm{dm}^{3}$ de nitrogênio para a maioria das características avaliadas. O processo de senescência destas forrageiras acelera com o aumento das doses de nitrogênio, reduzindo a duração de vida das folhas.

Palavras-chave: Brachiaria brizantha, Brachiaria decumbens, filocrono, perfilhamento

\section{Morphogenetic and structural characteristics of two grasses submitted to different nitrogen doses}

\begin{abstract}
The objective of this work was to evaluate the morphogenetic and structural characteristics of Brachiaria brizantha and decumbens submitted to different nitrogen doses $(\mathrm{N})$. The experiment was carried in a greenhouse. The treatments consisted of four $\mathrm{N}$ doses $\left(0,75,150\right.$ and $225 \mathrm{mg} / \mathrm{dm}^{3}$ of $\mathrm{N}$ ) and two grasses (Brachiaria brizantha and decumbens). Nitrogen fertilization was subdivided into three applications. A completely randomized block experimental design with five repetitions was used. For the morphogenetic and structural characteristics, the daily foliar structure emergence, total number of leaves and number of tillers per B. decumbens plant was higher for B. brizantha. However, for phyllochron, the daily foliar prolongation and life duration of the B. brizantha leaf were higher. B. decumbens and brizantha responded increasingly up to $190 \mathrm{mg} / \mathrm{dm}^{3}$ of nitrogen in relation to the majority the available characteristics. The process senescence is accelerated with increase of the nitrogen doses, reducing the life duration of leaves.
\end{abstract}

Key Words: Brachiaria brizantha, Brachiaria decumbens, phyllochron, tillering

\section{Introdução}

No estabelecimento de pastagens, atualmente destacam-se os capins do gênero Brachiaria, que apresentam vantagens em relação a outros gêneros, como boa adaptação a solos ácidos, tolerância à baixa fertilidade dos solos e elevado rendimento de matéria seca (Almeida, 1998).

Como a produção de folhas é prioridade na alimentação, para o bom manejo, é necessário conhecer e compreender não apenas o processo de transformação do pasto (forragem) em produto animal, mas sobretudo entender e controlar os processos de crescimento e desenvolvimento que resultam na produção da forragem a ser consumida. Dessa forma, quando se entende a dinâmica de crescimento e desenvolvimento das plantas que compõem uma pastagem e suas respostas morfofisiológicas aos fatores que as influenciam, torna-se mais fácil adequar o manejo do pasto visando à sustentabilidade do sistema de produção com alta produtividade dos componentes planta e animal, respeitando os limites ecofisiológicos das plantas forrageiras (Nascimento Júnior \& Adese, 2004).

Segundo Gomide \& Gomide (2000), a produtividade de gramíneas forrageiras depende da contínua emissão de folhas e perfilhos, processo importante para a restauração 
da área foliar após pastejo ou corte e que garante a perenidade à forrageira. A produtividade das pastagens pode ser estimulada por meio da adubação nitrogenada e pode variar quanto à dose utilizada e à espécie (Longnecker et al., 1993; Garcez Neto et al., 2002).

De acordo com Cecato et al. (1996), o crescimento e a persistência de gramíneas nos trópicos são freqüentemente limitados pela deficiência de nitrogênio no solo, uma vez que este nutriente acelera a formação e o crescimento de novas folhas e aumenta o vigor de rebrota, melhorando sua recuperação após o corte e resultando em maior produção e capacidade de suporte das pastagens.

O pasto em condição vegetativa pode ser definido pelas características e combinação das variáveis morfogênicas, de modo que o aparecimento foliar, o alongamento foliar e a duração de vida das folhas são as características mais importantes. A combinação dessas variáveis morfogênicas determina as principais características estruturais da pastagem: tamanho de folha, densidade populacional de perfilhos e número de folhas vivas por perfilho (Lemaire \& Chapman, 1996).

Objetivou-se avaliar as características morfogênicas e estruturais de Brachiaria brizantha cv. Marandu e Brachiaria decumbens cv. Basilisk adubadas com diversas doses de nitrogênio.

\section{Material e Métodos}

O experimento foi instalado na casa de vegetação pertencente ao laboratório de Forragicultura e Pastagens da Universidade Estadual do Sudoeste da Bahia, UESB, localizada no município de Itapetinga, Bahia, no período de abril a agosto de 2005. O experimento foi conduzido em esquema fatorial $4 \times 2$, utilizando-se diferentes doses de nitrogênio $\left(0,75,150\right.$ ou $\left.225 \mathrm{mg} / \mathrm{dm}^{3}\right)$ e duas espécies de braquiária (Brachiaria brizantha cv. Marandu e B. decumbens cv. Basilisk), em delineamento de blocos casualizados, com cinco repetições, totalizando 40 vasos plásticos com capacidade para $10 \mathrm{dm}^{3}$.

O solo utilizado foi proveniente do Campus da UESB e, em análise química, apresentou as seguintes características: $\mathrm{pH}=5,7 ; \mathrm{P}=1 \mathrm{mg} / \mathrm{dm}^{3} ; \mathrm{K}=0,10 \mathrm{cmol} / \mathrm{dm}^{3} ; \mathrm{Ca}=$ $3,7 \mathrm{cmol} / \mathrm{dm}^{3} ; \mathrm{Mg}=2,0 \mathrm{cmol} / \mathrm{dm}^{3} ; \mathrm{Al}=0,2 \mathrm{cmol} / \mathrm{dm}^{3}$; soma de bases $=5,8 \mathrm{cmol} / \mathrm{dm}^{3}$; capacidade de troca de cátions a pH 7,0 = 7,9 cmol $/ \mathrm{dm}^{3}$; saturação por bases $=73 \%$; matéria orgânica $=10 \mathrm{~g} / \mathrm{dm}^{3}$. Considerando os resultados da análise do solo, realizou-se a seguinte adubação por vaso: $2,5 \mathrm{~g}$ de superfosfato simples ( $45 \mathrm{mg} / \mathrm{dm}^{3}$ de $\mathrm{P}_{2} \mathrm{O}_{5}$ ) e $0,52 \mathrm{~g}$ de cloreto de potássio $\left(30 \mathrm{mg} / \mathrm{dm}^{3}\right.$ de $\mathrm{K}_{2} \mathrm{O}$ ) dissolvidos em
$500 \mathrm{~mL}$ de água e aplicados nove dias após o transplante das mudas. As plantas foram irrigadas todos os dias para garantir boas condições de crescimento. As temperaturas mínimas, máximas e médias foram registradas no período e resultaram em valores de 19,35 e $27^{\circ} \mathrm{C}$, respectivamente.

A semeadura foi realizada em canteiros de areia pelo transplante de quatro plântulas por vaso 19 dias após a emergência. O corte de uniformização foi realizado 49 dias após o plantio a $5 \mathrm{~cm}$ da superfície do solo. As doses de nitrogênio foram parceladas em três aplicações a cada 20 dias, com a primeira adubação no dia do corte de uniformização.

O estudo das características morfogênicas e estruturais foi realizado utilizando-se um perfilho por planta, identificado com fios coloridos. Este estudo iniciou-se no terceiro dia após o corte de uniformização, com medições a cada três dias, durante 60 dias. Registraram-se o aparecimento do ápice foliar, o dia da exposição da lígula, o comprimento da lâmina foliar expandida e em expansão, o número de folhas por perfilho e o número de perfilhos por planta.

A taxa de alongamento foliar (TAlF) foi calculada com base no comprimento das folhas em expansão. A lâmina foliar foi medida até sua expansão completa, ou seja, até o aparecimento da lígula, e foi expresso em milímetros. A taxa de aparecimento foliar (TApF) foi obtida pela divisão entre o número de folhas surgidas nos perfilhos marcados e o número de dias envolvidos, enquanto o filocrono correspondeu à forma inversa de cálculo da TApF.

A duração de vida da folha (DVF) foi estimada considerando o tempo entre o aparecimento do ápice e o primeiro sinal de senescência da lâmina foliar.

O número total de folhas por perfilho (NTF) foi obtido por meio da contagem do número de folhas em expansão, expandidas, senescentes e mortas dos perfilhos avaliados e o número de perfilhos por planta (NPP).

Os resultados foram submetidos à análise de variância, considerando como fontes de variação as espécies, a adubação e a interação espécies $\times$ adubação, testados a 5\% de probabilidade. A interação foi desdobrada, ou não, de acordo com a significância e o efeito do nitrogênio foi avaliado por análise de regressão, por meio de polinômios ortogonais, pela decomposição da soma de quadrado de nitrogênio em efeitos linear, quadrático e cúbico. As espécies foram comparadas pelo teste $\mathrm{F}$.

\section{Resultados e Discussão}

A interação espécies $\times$ doses de nitrogênio não foi significativa $(\mathrm{P}>0,05)$ para a $\mathrm{TApF}$. Houve diferença estatística $(P<0,05)$ entre as duas espécies, uma vez que a 
TApF para a B. decumbens (0,15 folha/dia/perfilho) foi maior que para a $B$. brizantha (0,12 folhas/dia/perfilho), confirmando que essa variável pode ser influenciada pela espécie utilizada.

A adubação nitrogenada influenciou $(\mathrm{P}<0,05)$ a taxa de aparecimento foliar (Figura 1a), que foi maior com dose de $169 \mathrm{mg} / \mathrm{dm}^{3}$ de N (0,15 folha/dia/perfilho), de acordo com o modelo ajustado. Alexandrino et al. (2004), trabalhando com B. brizantha cv. Marandu, em vasos, adubadas com três doses de nitrogênio ( 0,20 e $40 \mathrm{mg} / \mathrm{dm}^{3}$ de N) e oito idades de colheita (0, 2, 4, 8, 16, 24, 32 e 48 dias), verificaram

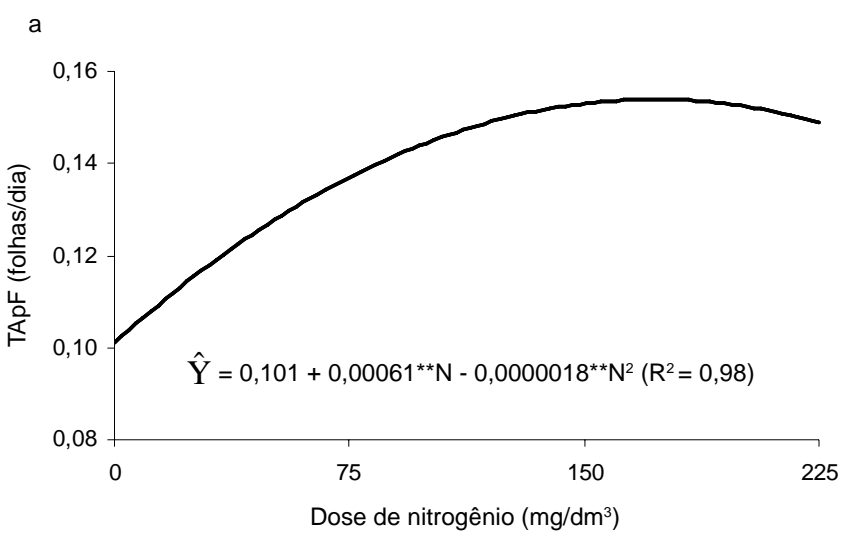

c
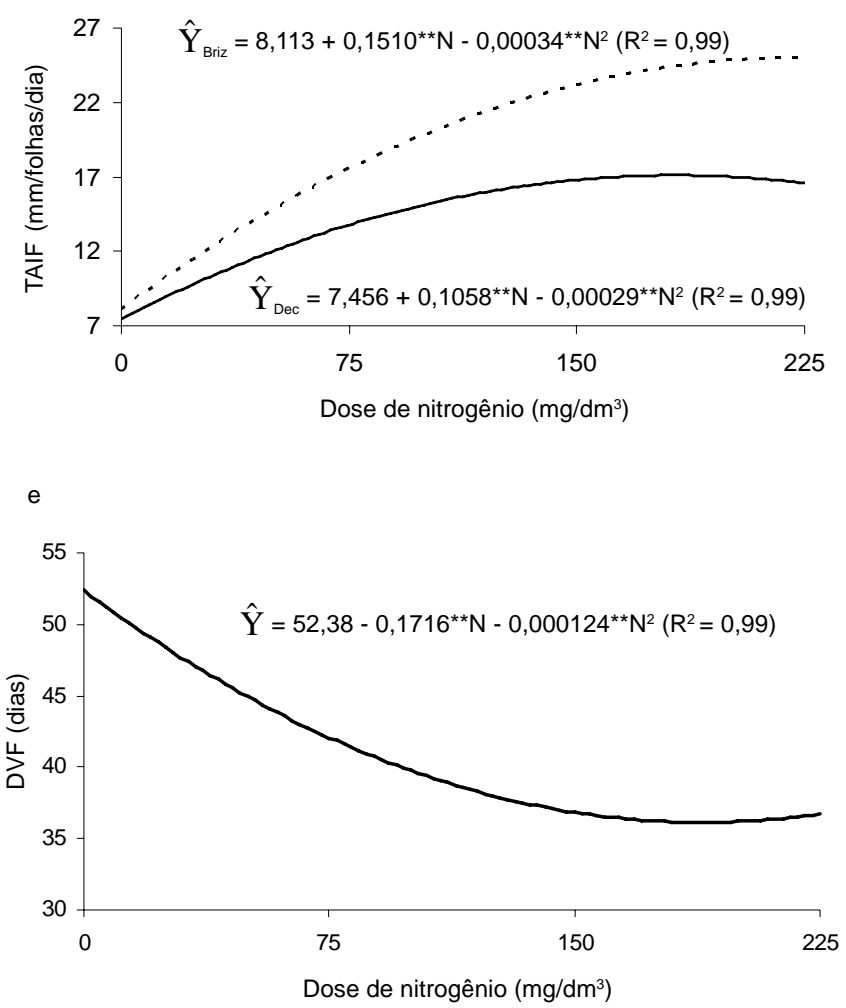

efeito linear das doses de nitrogênio sobre a TApF. Essa diferença no padrão de resposta ao nitrogênio, nos dois experimentos, possivelmente esteve relacionada às menores doses de nitrogênio testadas por esses autores.

O filocrono, definido como o tempo, em dias, para aparecimento de duas folhas sucessivas, foi influenciado $(\mathrm{P}<0,05)$ pela interação espécies $\times$ doses de nitrogênio. A adubação nitrogenada influenciou $(\mathrm{P}<0,05)$ o filocrono nas duas espécies estudadas. Decompondo o efeito das doses de nitrogênio em linear, quadrático e cúbico, observou-se que apenas o efeito quadrático foi significativo para
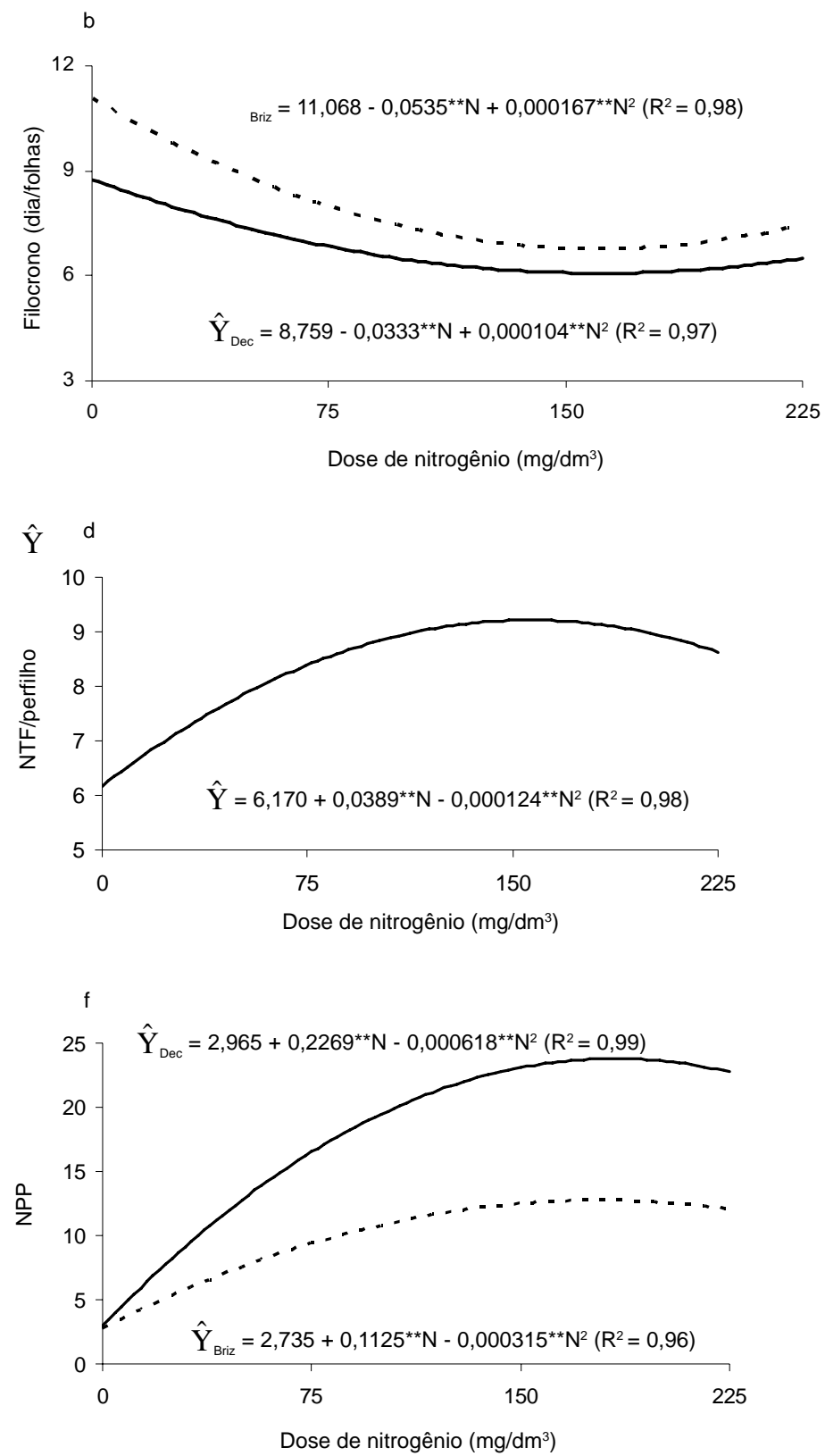

Figura 1 - Taxa de aparecimento foliar - TApF (a), filocrono (b), taxa de alongamento foliar - TAlF (c), número total de folhas - NTF (d), duração de vida das folhas - DVF (e) e número de perfilhos por planta - NPP (f) de Brachiaria brizantha e B. decumbens adubadas com nitrogênio. Significativo a $1 \%(* *)$. 
as duas espécies (Figura 1b). A B. brizantha teve como melhor resposta a dose de $160 \mathrm{mg} / \mathrm{dm}^{3}$ de $\mathrm{N}$, proporcionando assim, menor valor de filocrono estimado de 6,8 dias/folha. Na B. decumbens, a dose que proporcionou menor valor de filocrono foi de $160 \mathrm{mg} / \mathrm{dm}^{3}$ de $\mathrm{N}$ com filocrono estimado de 6,0 dias/folha.

A B. decumbens apresentou o menor valor de filocrono em relação a $B$. brizantha para todas as doses de nitrogênio. No entanto, o decréscimo foi maior quando aumentaram as doses de nitrogênio na $B$. brizantha. Esse resultado indica diferenças entre as duas espécies: a $B$. brizantha é classificada como gramínea de exigência nutricional média a alta, enquanto a $B$. decumbens é classificada como de exigência nutricional média a baixa.

Alexandrino et al. (2004), avaliando o filocrono em B. brizantha, verificaram que, com o aumento das doses de nitrogênio, o filocrono reduziu de 12,20 para 6,99 dias, respectivamente, nas plantas adubadas com 0 a $40 \mathrm{mg} / \mathrm{dm}^{3}$ de N, assim como Martuscello et al. (2005) encontraram valores de filocrono para o capim-xaraés de 11,45 e 8,81 dias sem adubação e com $120 \mathrm{mg} / \mathrm{dm}^{3}$ de $\mathrm{N}$, respectivamente.

Os resultados obtidos neste estudo, assim como os relatados na literatura, evidenciam a importância do nitrogênio na redução do tempo para o aparecimento de duas folhas sucessivas, uma vez que aumenta a produção de novas células, que tem reflexo positivo no número de folhas por planta. Esse fato tem relevância, pois as folhas são a parte da planta com maior valor nutritivo.

A interação espécie $\times$ dose de nitrogênio foi significativa $(\mathrm{P}<0,05)$ para a TAlF, que diferiu $(\mathrm{P}<0,05)$ entre as duas espécies e foi maior para a $B$. brizantha nas doses de 75 , 150 e $225 \mathrm{mg} / \mathrm{dm}^{3}$ de $\mathrm{N}$ em comparação à B. decumbens (Figura 1c). Na ausência de adubação nitrogenada, não houve diferença entre as espécies. A B. brizantha apresentou taxa de alongamento foliar superior à da $B$. decumbens, o que indica diferença entre as espécies.

A adubação nitrogenada influenciou a TAlF $(\mathrm{P}<0,05)$ (Figura 1c), pois a $B$. decumbens respondeu de forma positiva até a dose de $182 \mathrm{mg} / \mathrm{dm}^{3}$ de $\mathrm{N}$, com TAlF de 17,1 mm/folha/dia. A B. brizantha, no entanto, apresentou o maior valor (25,36 mm/folha/dia) na dose de $222 \mathrm{mg} / \mathrm{dm}^{3}$ de N. Segundo Fagundes et al. (2006), o efeito da adubação nitrogenada sobre a TAlF pode ser atribuído à grande influência do nitrogênio nos processos fisiológicos da planta.

Alexandrino et al. (2005) também observaram efeito quadrático das doses de nitrogênio $(0,45,90,180$ e $360 \mathrm{mg} / \mathrm{dm}^{3}$ de N) sobre a TAlF da $B$. brizantha cv. Marandu submetida a freqüências de corte a cada 28 dias e estimaram maior TAlF na dose de $293 \mathrm{mg} / \mathrm{dm}^{3}$ de $\mathrm{N}$.
Martuscello et al. (2005) observaram no capim-xaraés aumento de até $37 \%$ na TAlF quando aplicada a dose de $120 \mathrm{mg} / \mathrm{dm}^{3}$ de $\mathrm{N}$ em relação à ausência de adubação nitrogenada.

A interação espécie $\times$ dose de nitrogênio não foi significativa $(\mathrm{P}>0,05)$ para o número total de folhas por perfilho e para duração de vida das folhas. O número total de folhas por perfilho diferiu $(\mathrm{P}<0,05)$ entre as espécies e foi maior para $B$. decumbens (média de 8,8 folhas) e para B. brizantha (7,5 folhas).

A adubação nitrogenada influenciou $(\mathrm{P}<0,05)$ o número total de folhas por perfilho (Figura 1d) e a dose que proporcionou maior NTF/perfilho de 9,3 foi de $157 \mathrm{mg} / \mathrm{dm}^{3}$ de N. O número total de folhas por perfilho é uma variável importante da planta, pois influencia diretamente a produção de matéria seca. Silveira \& Monteiro (2007) também verificaram que as doses de nitrogênio influenciaram positivamente no número total de folhas em capim-tanzânia adubado com nitrogênio e cálcio, ajustando-se ao modelo quadrático de regressão.

A duração de vida das folhas diferiu $(\mathrm{P}<0,05)$ entre as espécies, de modo que os maiores valores foram observados para a B. brizantha (45,1 dias). Esse fato está relacionado à fisiologia diferenciada de cada espécie forrageira, que deve ser considerada no estabelecimento do intervalo de cortes, pois maior DVF possibilita maior intervalo de cortes.

A adubação nitrogenada reduziu $(\mathrm{P}<0,05)$ a duração de vida das folhas (Figura 1e) e a dose que proporcionou menor valor (36,1 dias) foi estimada em $191 \mathrm{mg} / \mathrm{dm}^{3}$ para ambas as espécies.

Com base nos resultados, pode-se inferir que as plantas, na ausência de adubação, permaneceram mais tempo com suas folhas vivas em detrimento da expansão de novas folhas, ou seja, o processo de senescência destas forrageiras é acelerado com aumento das doses de nitrogênio, reduzindo a duração de vida das folhas. Segundo Martuscello et al. (2005), a redução na duração de vida das folhas com a adubação nitrogenada pode ser explicada pela maior renovação de tecidos nas plantas.

A interação espécies $\times$ doses de nitrogênio foi significativa $(\mathrm{P}<0,05)$ para número de perfilhos por planta, que diferiu $(\mathrm{P}<0,05)$ entre as espécies nas doses de 75, 150 e $225 \mathrm{mg} / \mathrm{dm}^{3}$ (Figura 1f) e foi maior para a B. decumbens em relação à $B$. brizantha. Na ausência de adubação nitrogenada, o número de perfilhos por planta foi semelhante $(\mathrm{P}>0,05)$ entre as espécies. A adubação nitrogenada influenciou o número de perfilhos por planta $(\mathrm{P}<0,05)$ em ambas as espécies. As plantas que não receberam suprimento 
de nitrogênio praticamente não perfilharam. Alexandrino et al. (2004) também observaram incremento no perfilhamento da $B$. brizantha à medida que aumentaram a dose de nitrogênio.

Na espécie $B$. decumbens, o maior número de perfilhos por planta (23,8 perfilhos) foi obtido na dose de $184 \mathrm{mg} / \mathrm{dm}^{3}$ de N. Na B. brizantha, o maior número de perfilhos por planta (12,8 perfilhos) foi estimado na dose de $179 \mathrm{mg} / \mathrm{dm}^{3} \mathrm{de}$ $\mathrm{N}$, resultados que estão de acordo com os obtidos por Braga et al. (2004), que encontraram efeito quadrático do nitrogênio sobre o número de perfilhos em capimmombaça.

Maior número de perfilhos por planta proporciona maior cobertura do solo pela planta forrageira. Portanto, a adubação nitrogenada, além de aumentar a produção de matéria seca, contribui para a redução da degradação do solo, pois diminui a exposição ao impacto da chuva e a exposição ao sol. A B. decumbens, em relação a B. brizantha, proporciona maior cobertura do solo por apresentar maior número de perfilhos.

\section{Conclusões}

A taxa de aparecimento foliar, o número total de folhas e o número de perfilho por planta de Brachiaria decumbens são maiores que os de Brachiaria brizantha cultivados em casa de vegetação e adubados com nitrogênio. O filocrono, a taxa de alongamento foliar e a duração de vida da folha são maiores na espécie de Brachiaria brizantha. A Brachiaria decumbens e a Brachiaria brizantha respondem de forma crescente até a dose de $190 \mathrm{mg} / \mathrm{dm}^{3}$ de nitrogênio. O processo de senescência dessas forrageiras acelera com o aumento das doses de nitrogênio, reduzindo a duração de vida das folhas.

\section{Literatura Citada}

ALMEIDA, J.C.R. Combinação de doses de fósforo e magnésio na produção e nutrição de duas braquiárias. 1998. $81 \mathrm{f}$.
Dissertação (Mestrado em Agronomia) - Escola Superior de Agricultura Luiz de Queiroz, Universidade de São Paulo, Piracicaba, 1998.

ALEXANDRINO, E.; NASCIMENTO JR., D.; MOSQUIM, P.R. et al. Características morfogênicas e estruturais na rebrotação da Brachiaria brizantha cv. Marandu submetida a três doses de nitrogênio. Revista Brasileira de Zootecnia, v.33, n.6, p.1372-1379, 2004.

ALEXANDRINO, E.; NASCIMENTO JR, D.; REGAZZI, A.J. et al. Características morfogênicas e estruturais da Brachiaria brizantha cv. Marandu submetida a diferentes doses de nitrogênio e freqüências de cortes. Acta Scientiarum. Agronomy, v.27, n.1, p.17-24, 2005.

BRAGA, G.J.; LUZ, P.H.C.; HERLING, V.R.; LIMA, C.G. Resposta do capim-mombaça a doses de nitrogênio e a intervalos de corte. Acta Scientiarum. Animal Sciences, v.26, n.1, p.123-128, 2004.

CECATO, U.; GOMES, L.H.; ASSIS, M.A. et al. Avaliação de cultivares do gênero Cynodon. In: REUNIÃO ANUAL DA SOCIEDADE BRASILEIRA DE ZOOTECNIA, 33., 1996, Fortaleza. Anais... Fortaleza: Sociedade Brasileira de Zootecnia, 1996. p.114-116.

FAGUNDES, J.L.; FONSECA, D.M.; MISTURA, C. et al. Acúmulo de forragem em pastos de Brachiaria decumbens adubados com nitrogênio. Revista Brasileira de Zootecnia, v.35, n.1, p.21-29, 2006

GARCEZ NETO, A.F.; NASCIMENTO JR., D.; REGAZZI, A.J. et al. Respostas morfogênicas e estruturais de Panicum maximum cv. Mombaça sob diferentes níveis de adubação nitrogenada e alturas de corte. Revista Brasileira de Zootecnia, v.31, n.5, p.1890-1900, 2002 .

GOMIDE, C.A.M.; GOMIDE, J.A. Morfogênese de cultivares de Panicum maximum Jacq. Revista Brasileira de Zootecnia, v.29, n.2, p.341-348, 2000.

LEMAIRE, G.; CHAPMAN, D. Tissue flows in grazed plant communities. In: HODGSON, J.; ILliUS, A.W. (Eds.) The ecology and management of grazin systems. Wallingford: Cab International, 1996. p.3-36.

LONGNECKER, N.; KIRBY, E.J.M.; ROBSON, A. Leaf emergence, tiller growth, and apical development of nitrogen-deficient spring wheat. Crop Science, v.33, p.154-160, 1993.

MARTUSCELLO, J.A.; FONSECA, D.M.; NASCIMENTO JR. D. et al. Características morfogênicas e estruturais do capimxaraés submetido à adubação nitrogenada e desfolhação. Revista Brasileira de Zootecnia, v.34, n.5, p.1475-1482, 2005.

NASCIMENTO JR., D.; ADESE, B. Acúmulo de biomassa na pastagem. In: SIMPÓSIO SOBRE MANEJO ESTRATÉGICO DA PASTAGEM, 2., 2004, Viçosa, MG. Anais... Viçosa, MG: Universidade Federal de Viçosa, 2004. p.289-330.

SILVEIRA, C.P.; MONTEIRO, F.A. Morfogênese e produção de biomassa do capim-tanzânia adubado com nitrogênio e cálcio. Revista Brasileira de Zootecnia, v.36, n.2, p.335-342, 2007. 